\title{
The risk of blood-borne infections in Poland - opportunities and threats to public health, nationwide qualitative research
}

\author{
Anita Beata Gębska-Kuczerowska' ${ }^{1,2, A, C-F}$, Artur Błoński ${ }^{1, D-F}$, Mark Krol ${ }^{3, D, F}$, \\ Grzegorz Piotr Juszczyk k,B-C,E-F \\ ${ }^{1}$ National Institute of Public Health, Warsaw, Poland \\ ${ }^{2}$ Collegium Medicum, Cardinal Stefan Wyszynski University in Warsaw, Poland \\ ${ }^{3}$ Higher School of Logistics, Warsaw, Poland \\ ${ }^{4}$ Department of Public Health, Medical University of Warsaw, Poland \\ A - Research concept and design, B - Collection and/or assembly of data, C - Data analysis and interpretation, \\ $D$ - Writing the article, $E$ - Critical revision of the article, $F$ - Final approval of article \\ Gębska-Kuczerowska AB, Błoński A, Krol M, Juszczyk GP. The risk of blood-borne infections in Poland - opportunities and threats to public \\ health, nationwide qualitative research. Ann Agric Environ Med. 2021; 28(3): 469-474. doi: 10.26444/aaem/124709
}

\section{Abstract}

Introduction. The article presents the diagnosis of the problem of blood-borne infections in Poland from perspectives of experts' opinions at the voivodship level. The evaluation became the basis for subsequent analysis, aimed at creating assumptions for the proposed strategies to prevent blood-borne infections in Poland.

Materials and method. Diagnosis was based on the expertise of practitioners in epidemiology and service providers. Analysis covered assessment of service safety, examples, recommended practices, forms and scope of education. Also covered is information for the general public from different aspects: points of view of recipients and service providers, legislation, system organization, and finances. The SWOT method was used in analysis. The opportunities and threats concerning the risk of blood-borne diseases for the service sector are presented, as well as data gathered from 42 representative experts from across Poland.

Results. Databases on health indicators, covered by the reporting obligation of all diagnosed cases, are a crucial element of the surveillance system in public health (e.g. sentinel). Additional information on health care management (risk management) is not a common and routine approach. The study fills a gap in knowledge about risk management in the medical and non-medical services sector. The information also enriches education programmes (e.g. http://www.hcv.pzh.gov.pl/).

Conclusions. Currently, the evidence-based approaches in medicine and in public health are standard. Experts emphasize that the opportunities for the prevention of infection risk are linked to technological advances and innovations, while threats are seen in both financial and organizational constraints, and the non-normalized, dynamically developing service market.

\section{- Key words}

public health, threats, bloodborne infections risk, opportunities

\section{Abbreviations}

SWOT - Strengths, Weaknesses, Opportunities, Threats; WHO - World Health Organization; HCV - Hepatitis C Virus; HBV - Hepatitis B Virus; HIV - Human Immunodeficiency Virus; NGO - Non-Governmental Organization; NIPH-NIH - National Institute Public Health/National Institute of Hygiene; US CDC - Centers for Disease Control of United States

\section{INTRODUCTION}

Despite medical development, blood-borne infections is still a problem of concern to the World Health Organization (WHO) [1]. Blood can be a source of various additional antigens, including pathogens [2,3], as well as past medicinal products which might be a source of infection [4]. It has been proved that blood-borne infections are often etiologically associated with HBV, HCV, HDV, and HIV [5]. In Canada, systematic reviews (research data 1996-2016) were carried out to develop assumptions for a programme for the prevention of blood-borne infections It was estimated that the risk of infection transmission depended on many factors. Pathogen analysis (HCV, HIV, HBV) has shown that the risk of bloodborne infections is the highest for the infection (pooled

Address for correspondence: Anita Beata Gębska-Kuczerowska, National Institute of Public Health, Warsaw, Poland

E-mail: agkucz@vp.pl

Received: 14.11.2019; accepted: 19.06.2020; first published: 16.07.2020 transmission rate) of $\mathrm{HBV}$ (1.45\%), followed by HCV (0.46\%), and to a lesser extent - HIV (0.0056\%) [6, 7]. The risk of the transmission of blood-borne infection is attributed to the violation of tissue continuity during medical and nonmedical procedures. The risk is for both the exposed service provider and the service recipient. Verbeek and Basnet in a meta-analysis of 45 studies (11 RCT, 15 follow-up, and 19 CSS) assessed that 1 out of 10 operations is at risk for sharp instrument injury [8]. Global epidemiological assessment of the risk of injury - infections among health workers concerned the need to implement a global policy for the prevention of needlestick injuries [9]. The prevalence of blood-borne infections in the population is also attributed to risky behaviors, e.g. in the UK in 2017-2018, the prevalence of blood-borne viruses was four times higher in the prison population than in the general population $(0.6 \%$ prison population vs. $0.16 \%$ in general population) [10]. Statistical data evidences the essence of the problem. Globally in 2017, 1.1 million people were newly infected with $\mathrm{HBV}$, and in 
2015, 1.75 million people were infected with HCV [11]. In 2016 - 162,471 people died from viral hepatitis and more from its complications [12].

$\mathrm{HBV}$ is widespread in the Central European Region, as well as worldwide. The prevalence of chronic hepatitis B, by world areas, is assessed at the intermediate level (2-8\%) [13]. Vaccination has meant that the problem has become less urgent, but still important. There have also been observations and reports of no immunoreactivity after the vaccination of adults (5-10\% of adults vaccinated) [14].

An often unappreciated problem is concomitant hepatitis $\mathrm{D}$ infection, in which worldwide, it is estimated that antiHDV positive patients cover $0.16 \%$ of the general population (aprox.12 million). Among HBsAg-positive patients, one-fifth developed disease complications (18\% cirrhosis, $20 \%$ HCC). In a meta-analysis of 282 studies ( 376 population samples from 95 countries), HBsAg-positive patients were tested for anti-HDV. Stockdale et al. estimated anti-HDV prevalence at $4.5 \%(95 \% \mathrm{CI} 3.6,5.7)$ among all HBsAg-positive patients, and $16.4 \%$ among those in hepatology clinics. The authors concluded that there is a need for more quality data to improve the precision of burden estimates [15].

According to a WHO report, in 2015 worldwide, 71 million people were living with chronic hepatitis $\mathrm{C}$ and 1.75 million were newy-infected. An intermediate prevalence (1-5\%) was noted in Eastern Europe, the Mediterranean region and also in the Middle East and parts of Africa and Asia. In Western Europe, Central America, Australia, and limited regions in Africa (including South Africa), the prevalence was in the lower range $(0.2-0.5 \%)$ [13]. Progress in pharmacotherapy facilitates the almost complete recovery of all patients with hepatitis $\mathrm{C}$, but recovery of their health does not guarantee the persistence of their immunity and simultaneously, does not protect against re-infection [16].

Some with hepatitis C also have HIV co-infection. In 2015, approx. 2.3 million patients with both HCV and HIV were diagnosed worldwide [17]. This is due to the possibility of similar transmission pathways for both infections [18]. Also in the case of HIV, the progress in patient pharmacotherapy improves the effectiveness of treatment, although there are reported cases of non-response to post-exposure therapy, and lack of seroconversion [19].

The problem of blood-borne infections (by known etiology) is a burden, and simultaneously the costs of viral hepatitis need be analyzed, as well as their impact on the health system [20]. There is a complexity in the issue of bloodborne infections, e.g. from the aspect of etiology, new or unresolved in diagnosis, and therapy problems. From the perspective of public health, this complexity implicates the need to take solutions in the field of infection prevention, and permanent surveillance in the service sector of the known risk of infection transmission, and also research development on as yet unknown risk factors.

\section{OBJECTIVE}

The aim of the research was to analyze the procedures used in the medical and non-medical services sectors for allowing the diagnosis of blood-borne transmission risk of infections. The analysis was intended to develop a diagnosis and guidelines for a programme of prevention and management of bloodborne infections in Poland.

\section{MATERIAL AND METHOD}

Qualitative research methods were used to identify the way of thinking and behavioural practices related to blood-borne infections. Previously, a pilot study had been conducted to assist with the selection of thematic areas and method of research. The respondents (experts and practitioners) were invited by mail to participate in the study, and the quality research performed according to scientific rules. Concise information on the scope and reasons for the research were described in the invitation. Interviews were conducted on a special forum platform by an external company - a professional female facilitator, and the course of the discussion was observed by the research team who had the possibility of modeling.

One of the aims of the project was to analyze the situation in different regions of the country. It was therefore decided that the project would be implemented via the Internet to collect as many different opinions as possible in forum discussion (both experts and practitioners) from all 16 provinces in Poland [21].

The research tool, a web-based research platform IdeaBlog, was used because of the following which were crucial critical for the project:

- the study may involve a large group of respondents;

- the study allowed longer and more convenient time, allowing for a deeper and broader coverage of the subject matter;

- the questions were not answered immediately which allowed the participants to consult other sources, gather feedback from colleagues and specialists or rethink the topic;

- the Internet tool allowed uploading additional materials and content;

- the method allowed anonymity of the individual participants by a code (3-letter, randomized code); this ensured that any existing relations between the participants in the service and the structural relations did not affect the responses.

Respondents selection; All invited specialists had at least 5 years of experience in the subject area of the issues they were dealing with in their professional work. The statements of all participants were anonymized and contained a threeletter, randomized code. Respondents in the study were asked to comment on the two topics over 5 days period (the list of discussed issues in the table 1 . below). They were also encouraged to support their statements with examples and data (specific figures) and were encouraged to document cases of good practices.

The study involved 42 registered individuals, representing various State institutions and the private service sector (also supported during the forum by others specialists and data). Almost half of the invited respondents declined registering on the research forum platform due to their duties. Some of them supported occasionally registered specialists. The key to the selection was practical, routine contact with the area of surveillance, prevention, and control of blood-borne infections. In addition, geographic location was important in that the participants represented all regions of the country. Using the web-based platform gave respondents the possibility to choose a comfortable place and time for participation in the research and to obtain/verify additional information (the evidence). 
Table 1. Brief plan of selected topics (based on pilot study)

1) The role of blood-borne infections in everyday work.

2) Analysis of the blood-borne infections risk, analysis of awareness.

3) Regulations and procedures to reduce the risk of blood-borne infections.

4) Regulation vs. practice: what is the practical implementation of the guidelines?

5) Monitoring and reporting of infectious disease: occupational exposure and patient/client exposure

6) Good/bad practices in daily work routines.

7) Education and training about blood-borne infections.

8) The role of finances in the prevention of blood-borne infections.

9) Importance of prevention procedures (e.g. disinfection process) in the reduction of blood-borne infections.

10) Patients and clients - their role in managing / preventing blood-borne infections.

The criteria for the selection of experts/specialists for the study were defined as follows:

- specialists from different fields of medicine, pharmacoeconomics, and other fields relevant to health care system, including epidemiology at the province level;

- epidemiologists at province level, called for the implementation of public health practices, in particular, the sanitary and epidemiological supervision;

- representatives of professional groups from medical and non-medical professions (hairdressing, cosmetology, tatooing, wellness);

- representatives of NGOs: non-government organizations representing scientific and professional societies (infectious disease specialists, epidemiologists); organizations implementing public health education.
Opinions of all the experts and practitioners were collected and subjected to SWOT analysis. The presented results were the basis for planning the next stages of the project (phases II and III), aimed at establishing the assumptions of the strategy for preventing blood-borne infections in Poland (prioritization of identified problems). Opinion: to establish the opportunities and threats was negotiated with respondents during the research forum.

\section{RESULTS}

The most important results of the study are presented in Table 2, in separately columns for opportunities and threats from the perspective of the public health system in the area of blood-borne diseases.

\section{DISCUSSION}

The presented material is the first stage from the summary of the research project commissioned by National Institute Public Health/ National Institute of Hygiene (NIPH-NIH) in July August 2016, within the framework of grant KIK 35. NIPHNIH commissioned the research company - NGO (NonGovernmental Organization) according to the previously designed protocol. The article presents the current state of the implementation of the regulations and recommendations in the health care and other, non-medical services, listed in the Polish Act of 5 December 2008, 'Preventing and Combatting Infectious Diseases and Infectious Diseases in Humans', i.e hairdressers, cosmeticions, wellness, and tattooists. To consider the clarification of systemic needs, the

Table 2. SWOT - prevention of blood-borne infections in terms of opportunities and threats to the service system

\begin{tabular}{|c|c|}
\hline OPPORTUNITIES & THREATS \\
\hline $\begin{array}{l}\text { Growing public awareness; increased knowledge of viruses and prevention of } \\
\text { infection (most experts believe that the propagation of knowledge, information } \\
\text { and instructions is the main way to prevent blood-borne infections, the fact } \\
\text { that people are already aware - is already considered as a base to build on). } \\
\text { Increasingly better pharmacological treatments (allowing to carry out } \\
\text { appropriate remedial action when there is a potential infection; the fact that it } \\
\text { is easier to prevent and live with the infection, if it has already occurred, may } \\
\text { change the general attitude to the problem). } \\
\text { Improved technical means: more disposable tools and safe technologies - } \\
\text { services in breaking issue continuity should be driven by tools that eliminate } \\
\text { the weakest link in most human systems. } \\
\text { Change in regulations about personal responsibility (this may result in } \\
\text { increased involvement of staff, both medical and non-medical, in active } \\
\text { prevention of blood-borne infections). } \\
\text { Use of the Internet and modern technologies in preventive campaigns (this } \\
\text { allows for relatively low-cost access to various social groups in a form tailored to } \\
\text { their specific needs, such as presentation of instructional videos, etc.) } \\
\text { The habit of searching for answers on the Internet (thanks to this, information } \\
\text { and social campaigns can be included in the natural behaviour of people, which } \\
\text { may increase the reach and effectiveness of information campaigns). } \\
\text { Increasing customer and patient interest in the quality and safety of service } \\
\text { (the medicalization of hygienic procedures causes their recipient to read more, } \\
\text { learn more, and therefore have a better chance of 'hitting' on information about } \\
\text { hazards and ways of prevention). } \\
\text { Increased awareness among professional groups and the search for practical } \\
\text { knowledge. } \\
\text { Lack of stigmatizing the image of HCV-infected people (thus it is possible } \\
\text { to undertake information/prevention activities without risking generating } \\
\text { negative social attitudes, which could have a negative impact on the situation } \\
\text { of infected people; lack of no need to overcome prejudices). }\end{array}$ & 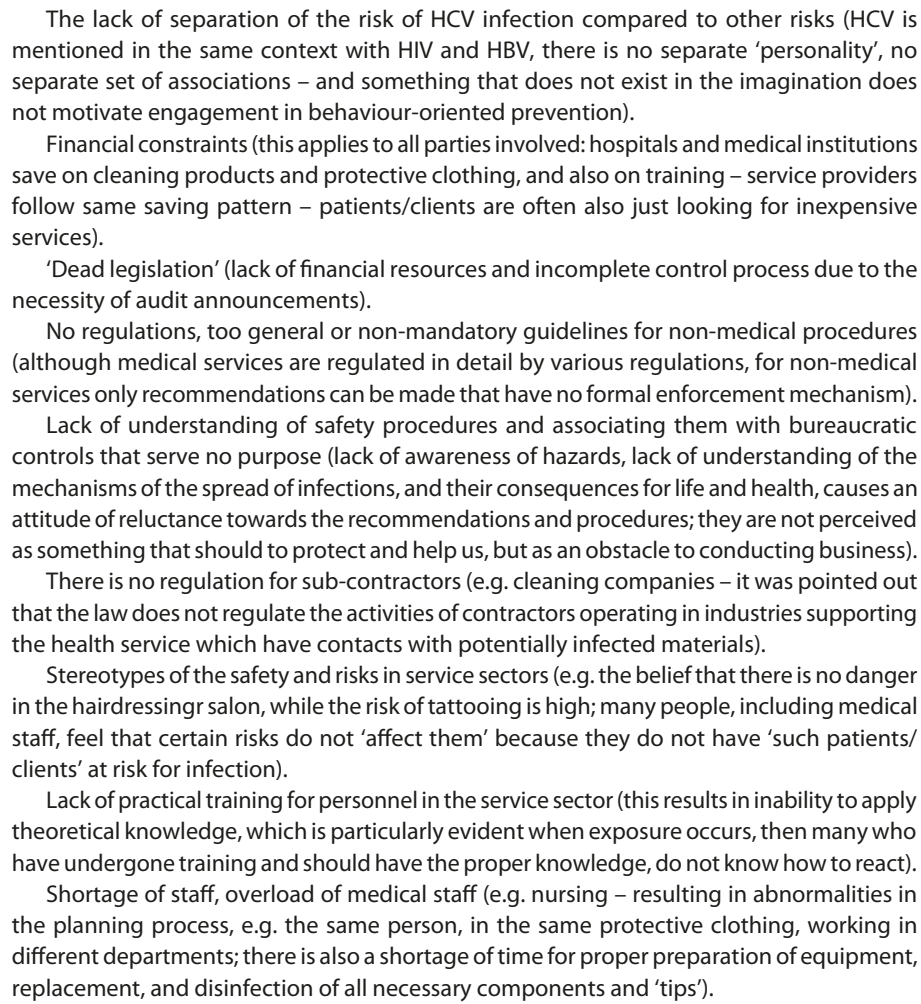 \\
\hline
\end{tabular}


problem was assessed from the perspective of epidemiological diagnosis and operational diagnosis - the perspective of public health. Analysis covered the state of knowledge, the way in which the existing regulations were implemented, and conscientiousness in reporting incidents of exposure, and financial aspects. The needs related to education in the area of blood-related infections (especially HCV) were also been discussed, and examples of good practices identified.

In order to adequately recognize the various issues related to this topic, it was decided to conduct the study with epidemiology experts and service providers whose daily work involved the risk of blood-borne infection, both in terms of being exposed to risk and creating a risk, and from the perspective of the institutions controlling compliance with the Act. In Poland, no similar analysis had carried out in this area; the form of the study and its results provided new facts and grounds for health policy.

The result of the project was a description of the key challenges in the area of infection related to the performance of medical and non-medical services, as well as proposals on how to respond to these challenges, and how to deal with the emerging difficulties, including the degree of the standards developed in the medical sector which can (should) be transferred to another service sector. A major challenge in the study was insight into the risk of blood-borne infection from the perspectives of experts and service providers.

The rationality of actions from the perspective of public health derives from knowledge of the specific nature of the problem. It is important to know the risk distribution and the possibility of finding an optimal place to stop the spread of infection, and be aware of other determinants $[13,22]$. Also, forecasting these phenomenon will affect the planning and rationalization of the activities [1, 23, 24]. Therefore, taking into consideration the health safety of services, an analysis was made of the scale of the occurrence of bloodborne infections and the diagnosis of the medical and nonmedical services system for these infections. The association of the risk of blood-borne infections with medical services is well known, and problem is incorporated in guidelines for preventing blood-borne infections. The risk is for both the recipients and the persons performing the treatments [25].

In the opinion of the invited specialists, the main threats affect 3 major areas: economic, functional, and awareness of risks and consequences of the threat. Economic threats include restrictions on the level of funding for public health services by public payers, and the unwillingness to finance safer but more expensive procedures in the cosmetic services sector. The problem of labor shortages is also a significant threat in the health sector which, when the demand for services is high, requires faster implementation of medical procedures and thus cause lack of time for sanitary procedures. Both these areas require changes at the whole health care system level, and they affect not only the system for the prevention of blood-borne infections. For example, in 2002-2011, in the British National Health Service, despite an increase in the funding and prevention programme in the area of protection against occupational exposures, a significant increase in such cases was observed - up to $60 \%$ [26].

There should be a continuous process of analysis which includes the proposal of solutions and drawing of conclusions. At the interface of economic and functional constraints, the issue of ineffective training and control mechanisms can be distinguished. Both elements require adequate funding to bring the expected effects (Training is focused on theoretical knowledge, which is cheaper to implement, while prevention is based in this case to a great extent on practical skills.). In addition, the functionality of the infection prevention system was limited by the lack of regulations governing non-medical "cosmetic surgeries" or subcontractors in the field of cleaning services.

Training to build practical skills related to avoiding the risk of blood-borne infection, should become a mandatory and permanent part of the preventive system. According to recommendations by experts, the public scope would allow them to be financed from public sources and thereby ensured free participation. The combination of free but compulsory participation can bring positive results, but this should be implemented with the focus on practical aspects. This means increasing the number of hours in which the leading specialists will be able to share experiences of the participants, present the correct techniques, allow training with feedback, i.e. analyzing mistakes. It also requires verification of acquired competencies during the training - at the end there should be a test of skills A significant finding after study of the results is also the need to shorten the training to an optimal number of hours, as each hour of training for participants means the loss of their income.

Training should be offered to people providing cosmetic services, especially because health care sector employees are protected quite effectively. A study published in 2013 showed, among other things, that the level of HBV and HCV infections among medical professionals in Poland is close to that in the general population. However, no research on this issue outside the health sector has been undertaken, and it should be assumed that the epidemiological situation may be different due to lack of procedures [27].

Formal confirmation of participation in the training and the final test should be verified during the entity inspection. It is to particularly important to conduct such inspections frequently and unannounced. When adjusting the training, the inspections should focus on assessment of skills, not only on the documentation. One of the purposes of inspections should be an evaluation of the errors, and a simultaneous lecture on the recommendations for changes. This approach should use the mentoring abilities of the controller, who would demonstrate the correct practices onsite.

The last indicated area of public health threats is awareness of risk of the level of blood-borne infection, which is imperfect among the medical staff and staff of nonmedical service sector, as well as patients and clients. Some researchers have pointed to several stereotypes regarding the 'security' of cosmetic services or the lack of communication on the prevention of HCV, identifying this as a separate health problem. Research conducted in Poland on a group of 192 dentists, showed that knowledge of the problem is insufficient, and up to $25 \%$ of professionals expressed an attitude of reluctance to treat patients infected with Human Immunodeficiency Virus (HIV), Hepatitis B Virus (HBV), and HCV [ibidem]. Similar fears about the risk of infection have also been revealed; at the same time, in studies by British medical specialists who recommended the implementation of an electronic case registration programme for occupational exposures in health care service [28].

Finally, according to the participants of the study, increasing the effectiveness of the system for the prevention of bloodborne infections will require a change in risk awareness 
in the whole society. The conclusion should also mention that in planning the campaign it is therefore important to consider the fact that increased population awareness will affect the costs of the system because of the desire to perform diagnostic tests [29].

Invited experts and practitioners looked at the chances for addressing the problem of blood-related infections by increasing public awareness, progress in pharmacotherapy, and greater accessibility to safe/disposable equipment.

Most experts believed that the promotion of knowledge, the information and instructions, is the main way to prevent blood-borne infections. Similar thoughts are presented by researchers in other countries [30]. Increased awareness among professional groups and clients/patients translates into the search for knowledge by professionals.

The respondents assessed that social awareness increased, in particular, the knowledge of viral infections and their prevention. As the experiences of other authors show, knowledge allows for rationale and safer choices to be made more effective at protecting and treatment on every stage of disease [31]. For most experts, chances are the innovation in medicine, especially in pharmacotherapy. With more effective treatment, it is also possible to carry out the appropriate remedial action in the event of a potential infection (exposure). The fact that they should be prevented more effectively and can be treated more effectively (live with less burden of infection - may change the general attitude to the disease and to stygmatization of patients).

On the other hand, the cost of blood-borne infections, diagnosis and treatment, increases with its effectiveness. This is one of the ways to achieve the aims of the WHO. Experts assess this goal to be difficult as it requires a significant increase in expenditures.

The Internet and other modern technologies which, in the hands of specialists are a valuable tool, are a great opportunity for promoting knowledge. (e.g. in campaigns, education profiles), which allow relatively low-cost access to various social group, and in a form that can be tailored to their specific needs. It also allows to use more interesting forms of education. For obvious reasons, they are not an alternative to contacting a professional, but the easiest way to impart the needed knowledge to specific recipients. For many of the experts participating in the study, the very common habit of searching for answers on the Internet was also a chance for them; as a result, information and social campaigns may enter into the natural behavior of people, which may increase the reach and effectiveness of information campaigns [32].

Technological advances bring more and better technical means to more areas, with more disposable tools and the need to guarantee safety. Services in violation of issue continuity should be carried out with tools that eliminate the risk of the "weakest link" in most systems, i.e. human error There are also discussions about the appropriateness and safety of reusing disposable equipment $[33,34]$. In the medical services sector, ethical issues are considered beyond the economic question. Knowledge gives a chance for a conscious choice of services. The respondents reported more and more interest from customers and patients, not only about costs, but also service quality and safety. In Poland, recent statistical data on HCV epidemiology indicates that the problem of the infections is still important, as well as the challenge for individuals and policymakers [35].
Among the proposed solutions, the respondents pointed to a change in regulations to increase personal responsibility. The expected effect of such amendments may be greater involvement of both medical and non-medical staff in the active prevention of blood-borne infections.

The invited experts did not acknowledge the stigmatizing image of infected people by treating such information as marginal. This makes it possible to carry out information and prevention activities without the risk of generating negative social attitudes which could have a negative impact on the situation of infected people; there is no need to break the negative prejudices. Negative attitudes and even escalation can be observed in the case of public communication also concerning other problems [36, 37].

\section{CONCLUSIONS}

Databases on health indicators, covered by the reporting obligation of all diagnosed cases, are a crucial element of the surveillance system in public health (Sentinel). Additional information on health care management (risk management) is not a common and routine approach. The study fills a gap in knowledge about risk management in the medical and non-medical services sector.

The information has enriched education programmes (e.g. http://www.hcv.pzh.gov.pl/).

Currently, the evidence-based approaches in medicine and in public health are standard. The experts emphasized that the opportunities in the prevention of infection risk are linked to technological advances and innovations, while threats were seen in both financial and organizational constraints and the non-normalized, dynamically developing service market.

From the perspective of the recent (2019-2020) COVID pandemic experiences, lessons have been learnt, the presented problems should also be looked at with awareness of the methodological limitations of the presented analysis. Knowledge of the pathways for spreading infections of known pathogens with the possibility of therapy gives the opportunity to control and to solve the problem. New pathogens without the possibility of therapy present challenge for science, old principles of prevention and humility. Do we know everything on blood-borne diseases etiology? New technologies can bring not only opportunities, but also new threats.

\section{REFERENCES}

1. WHO. Combating Hepatitis B and C to Reach Elimination by 2030. 2016 https://apps.who.int/iris/bitstream/handle/10665/206453/WHO_ HIV_2016.04_eng.pdf; jsessionid=23CD570FA9986402B8961AC37A $\overline{2}$ $\mathrm{C} 2 \mathrm{E} 4 \mathrm{~B}$ ?sequence $=1$ (Accessed 07.06.2020).

2. Chiu KP, Yu AL. Application of cell-free DNA sequencing in characterization of blood borne microbes and the study of microbedisease interactions. Peer J. 2019; 7: e7426. Published 2019 Aug 6. doi: $10.7717 /$ peerj.7426

3. Jaichenco AL, Lima LC. Infectious Disease Considerations for the Operating Room. A Practice of Anesthesia for Infants and Children. 2019; 1146-1160.e4. doi: 10.1016/B978-0-323-42974-0.00050-1

4. Mannucci PM. Viral safety of coagulation factor concentrates: memoirs from an insider. J Thromb Haemost. 2018; 16(4): 630-633. doi: 10.1111/ jth.13963

5. CDC. General Resources on Bloodborne Pathogens. Bloodborne Infectious Diseases (HIV/AIDS, Hepatitis B \& C). https://www.cdc. gov/niosh/topics/bbp/genres.html (Accessed 02.06.2020). 
6. Ogunremi T, Defalco K, Lynn Johnston B, et al. 1208. Preventing Transmission of Bloodborne Viruses from-Infected Healthcare Workers to Patients in Canadian Healthcare Settings: A National Guideline. Open Forum Infect Dis. 2019; 6 (Suppl 2): S434. Published 2019 Oct 23. doi: 10.1093/ofid/ofz360.1071

7. Ogunremi T, Defalco K, Johnston BL, et al. Preventing transmission of bloodborne viruses from infected healthcare workers to patients: Summary of a new Canadian Guideline. Can Commun Dis Rep. 2019; 45(12): 317-322. Published 2019 Dec 5. doi: 10.14745/ccdr.v45i12a03

8. Verbeek J, Basnet P. Incidence of sharps injuries in surgical units, a meta-analysis and meta-regression. Am J Infect Control. 2019; 47(4): 448-455. doi: 10.1016/j.ajic.2018.10.003

9. Bouya S, Balouchi A, Rafiemanesh H, et al. Global Prevalence and Device Related Causes of Needle Stick Injuries among Health Care Workers: A Systematic Review and Meta-Analysis. Ann Glob Health. 2020; 86(1): 35. Published 2020 Apr 6. doi: 10.5334/aogh.2698

10. Public Health England Health and Justice Review 2017/18. https:// assets.publishing.service.gov.uk/government/uploads/system/ uploads/attachment_data/file/725776/Health_and_Justice_Annual_ Review_2017-2018.pdf (Accessed 02.06.2020).

11. WHO. Progress report on access to hepatitis C treatment. Geneva World Health Organization; 2018. https://apps.who.int/iris/bitstream/ handle/10665/260445/WHO-CDS-HIV-18.4-eng.pdf?sequence $=1$ (Accessed 02.06.2020).

12. WHO. Global health estimates 2016. Geneva: World Health Organization; 2016. https://www.who.int/healthinfo/global_burden disease/estimates/en/ (Accessed 02.06.2020).

13. WHO. Global Hepatitis Report 2017. https://www.who.int/hepatitis/ publications/global-hepatitis-report2017/en/ (Accessed 02.06.2020).

14. Nicholson F. Infectious Diseases: The Role of the Healthcare Professional. Clin Forensic Med. 2020; 343-392. Published 2020 Jan 2. doi: 10.1007/978-3-030-29462-5_10

15. Stockdale AJ, Kreuels B, Henrion MYR, et al. The global prevalence of hepatitis D virus infection: systematic review and metaanalysis. J Hepatol. 2020. doi: https://doi.org/10.1016/j.jhep.2020.04.008

16. Treatment for hepatitis C. https://www.nhs.uk/conditions/hepatitis-c/ treatment/ (Accessed 02.06.2020).

17. Carter M. HIV and Chronic HCV co-infection prevalence in England highest with MSM. 2018 https://www.aidsmap.com/news/aug-2018/hivand-chronic-hcv-co-infection-prevalence-england-highest-amongmsm (Accessed 02.06.2020).

18. UK Cresswell F, Waters L, Briggs E, et al. UK guideline for the use of HIV Post-Exposure Prophylaxis Following Sexual Exposure, 2015. Int J Std AIDS. 2016; 27(9): 713-738. doi: 10.1177/0956462416641813

19. Hawkins DA, Asboe D, Barlow K, Evans B. Seroconversion to HIV-1 following a needlestick injury despite combination post-exposure prophylaxis. J Infect. 2001; 43(1): 12-15. doi: 10.1053/jinf.2001.0811

20. Razavi H, El Khoury AC, Elbasha E, et al. Chronic hepatitis C virus (HCV) disease burden and cost in the United States. Hepatology 2013 57: $2164-70$.
21. Denzin NK, Lincoln YS. Handbook of Qualitative Research. Sage Publishing, 2011.

22. Hagan H, Jordan AE, Neurer J, Cleland CM. Incidence of sexually transmitted hepatitis $\mathrm{C}$ virus infection in HIV-positive men who have sex with men. AIDS. 2015; 29: 2335-45.

23. WHO, Progress report on HIV, viral hepatitis and sexually transmitted infections, Accountability for the global health sector strategies, 20162021, 2019. https://www.who.int/publications-detail/progress-reporton-hiv-viral-hepatitis-and-sexually-transmitted-infections-2019 (accessed 03.06.2020).

24. WHO, Global health sector strategy on viral hepatitis 2016-21, 2016 https://apps.who.int/iris/bitstream/handle/10665/246177/WHO-HIV2016.06-eng.pdf?sequence $=1$

25. Fitz Simons D, Francois G, De Carli G, et al. Hepatitis B virus, hepatitis $C$ virus and other blood-borne infections in healthcare workers: guidelines for prevention and management in industrialized countries. Occup Environ Med. 2008; 65: 446-51.

26. Rice BD, Tomkins SE, Ncube FM. Sharp truth: health care workers remain at risk of bloodborne infection. Occup Med. (Lond). 2015; 65: 210-14.

27. Rybacki M, Piekarska A, Wiszniewska M, Walusiak-Skorupa J. Hepatitis $\mathrm{B}$ and $\mathrm{C}$ infection: is it a problem in Polish healthcare workers? Int J Occup Med Environ Health 2013; 26: 430-39.

28. Winchester SA, Tomkins S, Cliffe S, Batty L, Ncube F, Zuckerman M. Healthcare workers' perceptions of occupational exposure to bloodborne viruses and reporting barriers: a questionnaire-based study. J Hosp Infect. 2012; 82: 36-39.

29. Wakefield MA, Loken B, Hornik RC. Use of mass media campaigns to change health behaviour. Lancet 2010; 376: 1261-71.

30. McLean HS, Carriker C, Bordley WC. Good to Great: QualityImprovement Initiative Increases and Sustains Pediatric Health Care Worker Hand Hygiene Compliance. Hosp Pediatr. 2017; 7: 189-96.

31. Chen MF, Hung SL, Chen SL. Empowerment Program for People With Prediabetes: A Randomized Controlled Trial. J Nurs Res. 2017; 25: 99-111.

32. https://www.jestemświadom.org

33. Arora P, Kumari S, Sodhi J, et al. Gloves Reprocessing: Does It Really Save Money? Indian J Surg. 2015; 77 (Suppl 3): 1291-94.

34. Larose E. Legal implications of single-use medical device reprocessing. Health Q 2013; 16: 48-52.

35. https://pulsmedycyny.pl/gis-ka... (Accessed May 4th, 2020).

36. Sukhera J, Miller K, Milne A, et al. Watling C. Labelling of mental illness in a pediatric emergency department and its implications for stigma reduction education. Perspect Med Educ. 2017; 6: 165-72.

37. Hamilton JB, Worthy VC, Moore AD, et al. Messages of Hope: Helping Family Members to Overcome Fears and Fatalistic Attitudes Toward Cancer. 2017; 32: 190-97. 